Revista Iberoamericana, Vol. LXXVIII, Núms. 238-239, Enero-Junio 2012, 127-146

\title{
EL FUTURO OBTURADO: EL CRONOTOPO AISLADO EN LA CIENCIA FICCIÓN ARGENTINA POS-2001*
}

\author{
POR \\ Alejo Steimberg \\ Universidad de Extremadura
}

INTRODUCCIÓN: PRESENTACIÓN DEL CORPUS / ACLARACIÓN TERMINOLÓGICA

El término "ciencia ficción” evoca un conjunto específico de coordenadas narrativas espacio/temporales, un tipo particular de cronotopo. ${ }^{1}$ No existe, por supuesto, un cronotopo único para la ciencia ficción, pero una gran parte de las obras que en ella se encuadran suele situarse en el futuro, y esto independientemente del contexto de producción del relato en cuestión. La ubicación del relato en un futuro cercano o remoto es una constante en una parte importante de los relatos de ciencia ficción, tanto para la producción anglosajona o europea como en el contexto, menos canónico, de la ciencia ficción de otras latitudes.

En Postales del porvenir. La literatura de anticipación en la Argentina neoliberal (1985-1999), Fernando Reati (2006) construye un panorama de la producción argentina del género entre 1985 y 1999 en el que se confirma este predominio del futuro como marco temporal de la acción. Las obras analizadas tienen lugar en un futuro relativamente cercano y comparten, además, la particularidad de estar situadas en una línea histórica explícita, ya que suceden en un espacio-tiempo concreto cuyo origen se nos explica. Las novelas estudiadas tienen también en común la construcción de futuros distópicos, un hecho que Reati no deja de relacionar, ya desde el título, con el contexto de producción (la Argentina neoliberal).

Las obras que analizaremos aquí, dos novelas y una historieta en línea argentinas publicadas entre 2004 y 2009, pertenecen al período inmediatamente posterior al que toma Reati. Si bien el análisis de tres obras no puede aspirar a la representatividad, no puede dejar de observarse la ausencia del cronotopo dominante (una Argentina

\footnotetext{
* Mientras el presente volumen estaba en preparación, este trabajo resultó ser ganador del Vto. Jamie Bishop Award otorgado por IAFA (International Association for the Fantastic in the Arts) para el año 2011.

1 “[...] la correlación esencial de relaciones espacio-temporales, tal como ha sido asimilada por la literatura (Bajtin, “Forms” 84, traducción mía).
} 
en un futuro relativamente cercano) en las obras analizadas en Postales del porvenir. Efectivamente, Plop (2004), de Rafael Pinedo (1954-2006), y la novela gráfica en línea El cuervo que sabía (2008-2009), de Kwaichang Kráneo (alias de Carlos Lima, 1969), se ubican en escenarios posapocalípticos de los que no se conoce ni la ubicación temporal concreta ni el cataclismo que les dio origen (las marcas de una "argentinidad" o "latinoamericanidad”, que luego se explicitarán, sí siguen estando presentes, en mayor o menor medida). El caso de Donde yo no estaba (2006), de Marcelo Cohen (1951-), es aún más ambiguo, ya que ni la geografía ni la historia del mundo de la ficción parecen coincidir exactamente con el nuestro. Sin embargo, las menciones constantes a una época pasada en la que el paradigma religioso dominante era el del "Dios único" (fácilmente identificable al Dios judeocristiano), sumados a tópicos tecnológicos típicos de la ciencia ficción (Inteligencias Artificiales, ingeniería genética, implantes biotecnológicos, etc.), construyen un cronotopo fácilmente identificable como posfuturista (el prefijo se agrega para señalar su condición contrautópica y entonces conceptualmente alejada de la del que dio nombre a una de las "vanguardias históricas" de la modernidad) o al menos, como retroposfuturista o metaposfuturista. De la misma manera, diversos elementos funcionan como guiños de ojo que permiten un anclaje argentino y/o latinoamericano de la obra.

Si las obras tratadas por Reati estaban signadas por el contexto neoliberal, las que analizaremos son todas posteriores al estallido de diciembre de $2001,{ }^{2}$ a la crisis socioeconómica que sumergió al país y a la lenta recuperación posterior. Se trata de narraciones que tienen en común la falta de interés por los motivos del apocalipsis o por el apocalipsis en sí, que se concentran en la reconstrucción ulterior y que dejan de lado el aspecto de "advertencia" presente en muchas obras del género. Como si la debacle de un modelo (en este caso el neoliberal), la caída de un paradigma, más allá de la visión negativa que de él pueda mantenerse, obturase la posibilidad de la proyección; como si la única manera de imaginar un futuro consistiese en cortarlo casi completamente del contexto de producción de la obra, retomando la temporalidad de un presente eterno propia del imaginario tradicional posapocalíptico. Las novelas y la historieta elegidas no son, por supuesto, las únicas obras de ciencia ficción del mismo período que suceden en ese tipo de cronotopo: Promesas naturales (2006), de Oliverio Coelho (1977-), es otro ejemplo, y comparte además con Donde yo no estaba la ubicación en un cronotopo impreciso con rasgos identificables como posfuturistas y la presencia de marcas textuales que evidencian referencias culturales argentinas. ${ }^{3}$ Es

2 El entonces presidente Fernando de la Rúa abandonó la Casa de Gobierno en helicóptero el 20 de diciembre de 2001, en medio de protestas sociales callejeras que ignoraron el estado de sitio decretado poco antes.

3 Una de las castas de mutantes que pueblan la novela recibe el significativo nombre de "grasitas". El término, reinstalado políticamente por Eva Perón ("la abanderada de los humildes”), hacía referencia a

\footnotetext{
Revista Iberoamericana, Vol. LXXVIII, Núms. 238-239, Enero-Junio 2012, 127-146 ISSN 0034-9631 (Impreso) ISSN 2154-4794 (Electrónico)
} 
justamente debido a esos parecidos que no se la incluye en el presente análisis, ya que se ha preferido elegir obras que, así sea a partir de sus diferencias, ilustren de todos modos diferentes posibilidades de un mismo tipo de cronotopo.

Lo posapocalíptico, entonces, es de suma importancia en el corpus elegido, pero este imaginario debe por supuesto ser analizado en el contexto genérico en el que las obras se inscriben, que es el de la literatura de ciencia ficción. Es importante, por lo tanto, utilizar una definición de ciencia ficción operativa que aporte al análisis de las obras. En ese sentido, nos parece que la proporcionada por Darko Suvin sigue siendo sumamente útil, ya que parte de una clasificación general de toda la producción literaria tomando como parámetro principal la relación del mundo de la ficción o mundo secundario con el mundo primario, el contexto de producción de la obra. Suvin considera la ciencia ficción como parte de la "ficción distanciada", que es la ficción que construye mundos que presentan un novum (o varios nova), un elemento o característica imposible en el mundo primario que constituye el contexto de producción de la obra (Pour une poétique 25). Los diferentes géneros de la ficción distanciada introducen nova que mantienen una relación distinta con las leyes naturales. Esta comparación se realiza a partir de la relación que establece cada género con las leyes naturales: la fantasy las ignora, el fantástico las transgrede y la ciencia ficción las explota (16). Todos los géneros de la ficción distanciada ponen en escena mundos "otros”. En el caso de la ciencia ficción, esta otredad se construye a partir del discurso científico; el novum cienciaficcional debe ser validado por la lógica cognitiva (Suvin, Metamorphoses 63). Pero aún permaneciendo dentro de la ciencia ficción es posible establecer distinciones entre los tipos de nova.

En su artículo "Worlds Apart: A Theory of Science Fiction" ("Mundos aparte: una teoría sobre la ciencia ficción”), Carl Malmgren, partiendo de los aportes de Suvin, establece una definición de la ciencia ficción a partir de los mundos ficcionales que construye (25). La ciencia ficción, dice Malmgren, presenta mundos ficcionales cuyo sistema de actantes ${ }^{4}$ y cronotopos contiene al menos un factor de extrañamiento (un novum) con respecto al mundo empírico que se presenta naturalizado a través de un discurso científico. Pero para poder llegar a eso hace falta establecer una estructura básica general de los mundos de ficción, y eso es lo que Malmgren hace al dividir en tres grupos los componentes básicos de todo mundo ficcional: un conjunto de actantes, una estructura social que regula sus interacciones y un espacio físico o topos que respeta una serie de leyes naturales (que también pueden ser propias del mundo en

las partes más desfavorecidas de la población. En boca de las clases altas y medias altas, "grasa” cobró un fuerte matiz despectivo y pasó a referirse, como adjetivo, a los rasgos estilísticos de las clases más bajas.

4 Greimas propone el concepto de "actante” para reemplazar al de "personaje” de Propp (173). El esquema actancial de Greimas se compone de seis categorías de actantes, organizados en tres pares opuestos: sujeto/objeto, destinador/destinatario, oponente/ayudante.

$\begin{array}{lllll}\text { Revista Iberoamericana, Vol. LXXVIII, Núms. 238-239, Enero-Junio 2012, 127-146 } & \text { ISSN 2154-4794 (Electrónico) }\end{array}$ 
cuestión) (25). En todo mundo cienciaficcional, el novum o los nova en cuestión se insertarán en uno o más de estos sistemas. Para determinar el punto de comparación a partir del cual evaluar el novum (es decir, el del parámetro a considerar para determinar si determinado elemento del mundo de ficción constituye o no un novum), Malmgren sigue también a Suvin, para quien este “mundo básico narrativo” corresponde al “mundo cero" de propiedades empíricamente verificables en el que vive el autor de la obra en cuestión (Metamorphoses 11). Esto resulta coherente, ya que si la ciencia ficción especula o proyecta lo hace forzosamente desde un punto de partida que no puede dejarse de lado en el momento del análisis de la obra. Malmgren toma prestado a Rabkin el término "grafolecto” para designar "una práctica de escritura cuyo discurso está marcado diacríticamente con la huella de una matriz cultural, sociológica e histórica específica” (27, mi traducción). El grafolecto, continúa Malmgren, distingue a la "voz" que escribe como proviniendo de un tiempo, lugar y grupo social específico.

El nova seminal en las tres obras que analizaremos aquí es, evidentemente, un cataclismo que cambia el rostro del mundo de manera definitiva. En la mayoría de los casos, un apocalipsis cuya presencia es explícita en forma de ruinas o de referencias directas; en Donde yo no estaba se trata de un cataclismo en sordina, cuya existencia se deduce por los diversos elementos que instalan el mundo de la ficción como una versión futura de la Tierra de principios del siglo xxi. A este nova se agregarán otros a otros niveles, como el de las costumbres o el orden social. En todos los casos, la reconstrucción (o el intento de reconstrucción) de un mundo a partir de un evento que lo transformó de manera drástica ${ }^{5}$ ocupa un espacio central; y lo mismo ocurre con la presencia de grafolectos que hace referencia, de manera más o menos evidente, más o menos constante, a diferentes formas de lo argentino o lo latinoamericano. Se trata, en todas las obras, de cronotopos posapocalípticos “aislados” (lo cual es coherente ya que todo posapocalipsis, en tanto que mundo poshistórico o ahistórico, está aislado y separado de la continuidad) que no por eso dejan de mostrar las huellas de una “argentinidad” o "latinoamericanidad” que parecen mostrarse, por su supervivencia, casi como indelebles. Otro paso esencial para el análisis es, entonces, tener en claro cuáles son los rasgos de lo “posapocalíptico”.

James Berger, en el primer capítulo de After the End, analiza la particular paradoja de los relatos apocalípticos:

The apocalypse [...] is The End, or resembles the end, or explains the end. But nearly every apocalyptic text presents the same paradox. The end is never the end. [...] In

\footnotetext{
5 En Donde yo no estaba la reconstrucción (y, por ende, la destrucción previa) es menos física que simbólica: la «religión del Dios único» (que no puede no interpretarse como una referencia al monoteísmo de raíz judeocristana) ha sido desplazado por la otra religión, la del Pensar, con todas las consecuencias que un cambio tal puede implicar en la cosmovisón de una civilización.
}

\footnotetext{
Revista Iberoamericana, Vol. LXXVIII, Núms. 238-239, Enero-Junio 2012, 127-146 ISSN 0034-9631 (Impreso) ISSN 2154-4794 (Electrónico)
} 
nearly every apocalyptic presentation, something remains after the end. [...] In modern science fiction accounts, a world as urban dystopia or desert wasteland survives. (5)

The study of post-apocalypse is a study of what disappears and what remains. (7)

Esos “mundos de después del fin” suelen tener determinados rasgos en común. Como señala Berger, en la ciencia ficción lo que suele sobrevivir es una tierra baldía o una distopía urbana, como ocurre en las ficciones encuadrables dentro de la rama del cyberpunk. ${ }^{6}$ De las obras que analizaremos aquí, dos construyen mundos que reflejan la primera opción (un inmenso basural en el caso de Plop, un desierto en el de El cuervo que sabía), mientras Donde yo no estaba tiene más en común con los futuros tecnológicos y semi-totalitarios de las obras de Gibson y otros. En todos los casos, los mundos construidos dan cuenta de una "territorialización"7 específica (con rasgos de lo argentino o lo latinoamericano) del cronotopo posapocalíptico utilizado.

Berger (9) también define el posapocalipsis posmoderno (como el retratado en las obras de ciencia ficción) como el espacio de la pos-historia. Efectivamente, en las obras que trataremos aquí la historia (o al menos una historia) parece haber terminado. Por la desaparición de la especie humana en El cuervo que sabía, y por ende de toda transmisión de memoria, y por la destrucción de la civilización tal y como la conocemos en Plop. En Donde yo no estaba, por su lado, lo poshistórico se evidencia en un presente continuo en el que, por ejemplo, ni la tecnología ni la moda parecen ya cambiar demasiado. ${ }^{8}$

Frank Kermode en el capítulo "The Modern Apocalypse” de The Sense of an Ending (1967), también se explaya sobre la anulación del paso del tiempo como efecto del apocalipsis: hablando específicamente sobre el sentido contemporáneo de “crisis”, sostiene que si los momentos que llamamos crisis son fines y comienzos, una particularidad de nuestra imaginación es que elige constantemente estar en el final de una época (96-97). Kermode señala también que la etapa de transición, durante la cual

6 Neuromancer (1984) de William Gibson (1948-), es una de las obras señeras de esta corriente. La novela de Gibson presenta los rasgos básicos que se convertirían en una constante del cyberpunk: la existencia de un sistema político distópico (en el caso de Gibson, un mundo dominado por las corporaciones); un gran desarrollo tecnológico que se manifiesta en forma de un gran abanico de artefactos (Inteligencias Artificiales, cyborgs, etc.); y la presencia de dispositivos (tecnológico-químicos y/o producto de las facultades mentales) que compiten con la realidad material, la suplantan y eventualmente llegan a constituir un continuo indiferenciable con ella.

7 Ya habíamos empezado a trabajar la apropiación "no desterritorializada” de la ciencia ficción en la novela de Cohen en nuestro artículo "El posapocalipsis rioplatense de Marcelo Cohen. Una lectura de Donde yo no estaba" (Steimberg).

8 Líber mí, un folletín de "pantallátor" que fascina a los hijos de Aliano, el protagonista, se revela ser de la época de Carlos Mench, el escritor favorito de Aliano, muerto hace muchos años, que tampoco se precisan (Cohen, Donde 491-92).

Revista Iberoamericana, Vol. LXXVIII, Núms. 238-239, Enero-Junio 2012, $127-146$
ISSN 0034-9631 (Impreso) 
coexisten el pasado y el futuro, se ha vuelto eterna (100-2): la creencia de que la propia época es transicional se modifica y la transición pasa a ser una época en sí. El efecto de movernos de transición en transición tiene por efecto que nuestra existencia no establece ni relaciones inteligibles con el pasado ni relaciones predecibles con el futuro. Esto se verifica, en cada caso de una manera distinta, en las tres obras seleccionadas. La civilización de las ruinas de Plop, con sus sociedades de cazadores-recolectores que viven de desechos industriales, es un ejemplo casi literal de mezcla de épocas, con su presente eterno de supervivencia. Donde yo no estaba multiplica las evidencias de una temporalidad paralizada: el mundo de la ficción, el Delta Panorámico, muestra un avanzado estadio tecnológico que, paradójicamente, parece no cambiar desde hace eras. ${ }^{9} \mathrm{Y}$, en El cuervo que sabía, el pasado se hace presente en forma de fragmentos inconexos, mientras la posibilidad de un futuro (al menos al comienzo del relato) ni siquiera se plantea. Pero más allá de la forma de la construcción de los mundos posapocalípticos, que es comparable con la que realizan otras narraciones de ciencia ficción, es esencial el carácter “territorializado” de los cronotopos puestos en escena.

Plop, de Rafael Pinedo, o el mundo como Residuo

El mundo que se nos presenta en Plop es un mundo de restos: restos de construcciones, de objetos, de costumbres. En una llanura de basura y barro, la flora y la fauna han quedado reducidas a los campeones de la supervivencia de cada reino. Arbustos espinosos, arañas, gusanos, gatos, ratas, cerdos, perros salvajes y hongos (algunos comestibles, muchos venenosos) constituyen el exiguo panorama de las formas de vida restante, en un dominio absoluto de parásitos o depredadores que compiten entre sí. Y entre ellas, como un carroñero más, el hombre.

Nada se crea: todo es reutilización. No queda nada entero, todo es resto y fragmento. Fragmentos (de cemento, plástico, vidrio, lata, metal casi siempre con óxido) son los materiales a la disposición de los habitantes del "grupo" (como se llama a los colectivos humanos existentes) en el que nace el protagonista Plop (bautizado así por el ruido hecho al nacer cayendo en el omnipresente barro). Y de fragmentos también es la cultura de esos grupos humanos, con palabras y expresiones venidas de épocas olvidadas y resignificadas en ese mundo del barro y la basura. Una cultura del reciclado absoluto, del que no escapan (del que sobre todo no escapan) los cuerpos humanos. El reciclado es el destino del inútil, del viejo, del débil, del enfermo; del que es, por su sola existencia, un obstáculo para la supervivencia del grupo. Es un

9 Ninguno de los libros que cita el diario de Aliano (la forma que adopta la novela) da cuenta de otras coordenadas tecnológicas: ni el libro de Mench ni el Libro del Yud, el libro canónico de la Religión del Pensar, en el que aparecen "monitorios", las inteligencias artificiales que supervisan el estado de las viviendas (Cohen, Donde 400).

$\begin{array}{lllll}\text { ISSN 0034-9631 (Impreso) } & \text { ISSN 2154-4794 (Electrónico) }\end{array}$ 
mundo en el que todo se usa, empezando por las personas: usar, efectivamente, es la manera habitual de referirse al sexo. Este es un mundo en el que nada se produce y en que sus habitantes no pueden ser otra cosa que cazadores (de ratas, de gatos, de otros hombres) y recolectores (de basura y de restos para reciclar); un mundo en el que afloran, como basura flotando en el agua (agua que no puede tomarse porque brilla de noche una vez toca el suelo), rastros de otras épocas, sin que nadie identifique o le importe ese origen. No son más que restos, y los restos se usan. Esos restos afloran a veces en forma de palabras que conservan muchas veces el esqueleto o el fantasma de lo que a veces significaron. Así la "Plaza" es el espacio vacío que se deja en medio de cada Asentamiento (siempre precario y temporario) del grupo (Pinedo 18). Y, sin embargo, pese a que lo queda de cultura sean residuos, hay algo más peligroso que la basura (que puede matar, en forma de hierros retorcidos que se clavan en la carne): la ausencia de ésta, o sea, la naturaleza: “[...] existen lugares donde hay más matorrales que basura. Pero son peligrosos, ahí andan animales. Por lo general, el que entra no sale” (21). Los habitantes del mundo de Plop siguen sintiendo como propio el espacio de la cultura frente al espacio de la naturaleza, aunque su cultura sea una cultura de la basura. Porque la basura, entendida como algo que sobra y no puede ser absorbido por la naturaleza, no puede sino ser obra humana.

Las sobras del pasado utilizadas por los habitantes del mundo de Plop son las que sirven o no desentonan con una forma de vida centrada únicamente en la supervivencia, en el combate cotidiano por la vida. En ese contexto, es coherente que la organización interna del grupo de Plop sea heredera de estructuras militares y policiales: el líder máximo recibe el nombre de Comisario General, las tareas se dividen por un sistema de brigadas (15-16), y en casos específicos se forman células (37). Y como parte de este universo policíaco-militar, como su contracara, se incorporan códigos de la cultura carcelaria, se llaman "púas" a los cuchillos (21), por ejemplo.

Los grupos humanos que muestra Plop, entonces, volvieron a un modo de vida de cazadores-recolectores, de sociedad tribal con sus propias costumbres, organización y tabúes (22) que siempre funcionan, por supuesto, como reciclado de los de épocas olvidadas. Y es así como, pronto en la novela, nos enteramos del tabú del grupo de Plop: "[...] todos hablan mirando para abajo. Se ríen con la boca cerrada, gritan entre dientes. Nunca abren la boca” (22). El recitado completo del tabú en ocasión de la iniciación (la entrada en la vida adulta) de Plop y sus amigos, la Tini y el Urso, que incluye frases como "la comida se mastica, nadie la mira" o "en boca cerrada no entran moscas” (30), revela el material discursivo de origen del tabú. El grupo de Plop venera las briznas (en los ejemplos citados, de refranes o "buenas maneras"), fosilizadas y sacralizadas, del mundo previo a su presente eterno de basura y barro. Estos restos afloran, transformados y casi irreconocibles, en los ritos y costumbres del grupo de Plop. Veamos el ejemplo del que se explica en el capítulo "El Karibom”:

\footnotetext{
Revista Iberoamericana, Vol. LXXVIII, Núms. 238-239, Enero-Junio 2012, 127-146 
En la primera luna llena después del solsticio de invierno se celebraba el Karibom. Se sentaban los viejos en el centro de la Plaza. Con algunos tambores, con hierros y tachos, y empezaban a golpear rítmicamente: Ta, ta ta, tatá.

El resto de la gente caminaba en ronda. Al ritmo de los golpes. Eso podía durar toda la noche.

Estaba prohibido pelear o discutir. Ahí estaban todos. Las madres con sus chicos, los secretarios, las secretarias, el Comisario General y su mujer, los viejos, los jóvenes, hasta los esclavos de Voluntarios Dos. (27)

El festejo del Karibom muestra diversos puntos en común con el carnaval, además de cierto parecido en el nombre, aunque las fechas no coincidan. Como en las murgas del carnaval rioplatense, la percusión cumple un rol esencial. Y como es tradicional en el carnaval, ${ }^{10}$ se trata de un momento en el que se suspenden momentáneamente las diferencias sociales. La otra fiesta importante que se menciona en la novela se llama, precisamente, la Fiesta, y tiene lugar diez noches después del solsticio de verano, para el fin del calendario (43). ${ }^{11}$ Sólo queda el esqueleto de la celebración, sin referencia histórica ni mítica (“Jamás nadie dijo qué se conmemoraba”), y en una condensación que anula toda referencia concreta, las fiestas (Navidad y Año Nuevo), pasan a ser, simplemente, la Fiesta. Y hasta los entretenimientos son, también, fragmentos y residuos de juegos y deportes del pasado: durante el Karibom, Plop juega al tacle, que consiste en correr y tumbar al otro (43).

Los residuos del pasado, por escasos, son verdaderas reliquias, tanto los materiales como los simbólicos. Por eso, cuando la vieja Goro (la dueña de Plop, quien lo salvó de la muerte al nacer) lee en voz alta una descripción del Big Bang, todos los miembros del grupo, del primero al último, sin distinción de rango, la escuchan con veneración, aunque nadie entienda ni una palabra de lo que dice (46). Y es que un texto que habla de un origen carece de sentido en el presente de decadencia eterna del mundo de la novela. Y la adoración del pasado (de lo poco que queda de él) excede a la cultura: un árbol seco, sin hojas, es un objeto de atracción para todos, y hasta existe un grupo que vive para cuidarlo, autodenominado "Guardianes del árbol”. La veneración del grupo los lleva a un práctica exótica para el resto de los grupos: limpiar. El terreno que rodea al árbol presenta entonces sólo tierra (barro), sin alambre, vidrio o madera rota, lo que aumenta la singularidad del área: un espacio sin residuos sólo puede provenir del pasado. O así piensa la mayoría: unos pocos hablan de la existencia de una “Tierra

${ }_{10}$ Bajtin habla largamente al respecto en su célebre libro La cultura popular en la Edad Media y el Renacimiento.

11 Tomando en cuenta que los solsticios ocurren alrededor del 21 de junio y del 21 de diciembre, y las precisiones que se dan sobre la época de celebración del Karibom, queda definitivamente claro que el escenario de la novela es el hemisferio Sur. El Karibom es claramente el 31 de diciembre.

$\begin{array}{lllll}\text { ISSN 0034-9631 (Impreso) } & \text { ISSN 2154-4794 (Electrónico) }\end{array}$ 
Sana" donde no llueve siempre y de la que salen cosas llamadas plantas que dan comida, frutos; los llaman Mesías, y dicen saber cómo llegar a esa tierra única (101). Uno de estos mesías llega al grupo; Plop, que ya es el líder y sabe cosas que los otros no, está convencido de que el mesías no hace más que hablar del pasado y se las arregla para desembarazarse de él. Plop es un hombre de su época, una época sin futuro y con un pasado muerto y enterrado.

El mundo de Plop está plagado de residuos culturales e históricos. Muchos, como los mencionados más arriba, son indicios generales de una pertenencia a la cultura occidental. Pero también hay marcas mucho más específicas que construyen un cronotopo claramente anclado, en términos geográficos y culturales, en Argentina. Estas “marcas de territorialización” del mundo posapocalíptico relativamente típico de la ciencia ficción son de tres tipos: culturales, idiomáticas y geográficas. De las marcas idiomáticas, la más representativa y ubicua es el voseo. Los otros dos tipos, entonces, merecen ser observados con mayor detalle.

La ubicación geográfica se realiza prácticamente en una sola página, donde se nos describe un paisaje uniformemente llano ("La Llanura, la llaman”), sólo interrumpido por las omnipresentes pilas de basura. El breve capítulo proporciona más detalles: "Dicen los viajeros que lejos, a más de treinta días de camino, el suelo se levanta y hay partes de piedra y no hay cascotes ni latas. [...] A lo lejos, por donde sale el sol, de noche se ve un resplandor [...]. Dicen los viejos que todo es agua” (22). Una extensa llanura, limitada de un lado por montañas y del otro (el Este) por una inmensa extensión de agua. No resulta difícil, a partir de estas precisiones, ubicar el escenario de la novela, de manera general y apoyándose en el resto de los indicios, en una de las regiones más representativas y conocidas de Argentina, la Pampa (que excede a la provincia homónima). Por supuesto, esto resulta de importancia sólo para el lector. Los habitantes del mundo de Plop reciben estos relatos con la misma incredulidad ("nadie les cree", "son cuentos" [22]). Su mundo es un mundo de basura, sin límites ni cambios.

Ese mundo de residuos es un mundo de miseria y de pobreza, y la vida en ese mundo toma elementos, con toda lógica, de los rasgos con que se definen las zonas de pobreza extrema en la Argentina contemporánea y su emergente más visible, la "villa miseria". Los miembros del grupo de Plop viven en "casillas" de chapa, y sus campamentos temporarios se llaman "asentamientos", es una perennización de la cultura de la precariedad.

El cuervo que sabía, de Kwaichang Kráneo: pulsión y desierto o el Desierto de la PULSIÓN

El mundo de El cuervo que sabía es, en muchos aspectos, el opuesto del de Plop. Si el mundo de la novela de Pinedo es un mundo de restos, de sobras, el de la historieta

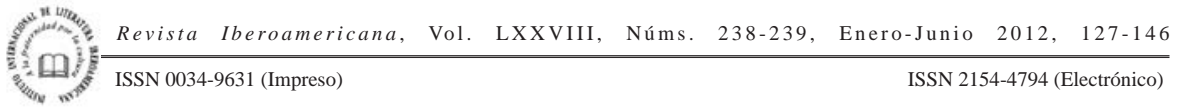


de Kráneo es un mundo en el que no queda casi nada. Aunque en ambos casos se trata de desiertos: un desierto de basura y barro en un caso, un desierto de roca y árboles petrificados en el otro, unidos por el hecho de ser mundos estériles.

La primera página de El cuervo (la página cero, en realidad, que hace las veces de “tapa” virtual) parece dar una idea bastante clara de lo que le espera al lector: ${ }^{12}$ la página está ocupada por una única viñeta que muestra a una figura humanoide (luego veremos que es un chico humano con un traje especial) sosteniendo lo que parece ser una foto de familia, contra un fondo indefinido y aparentemente rocoso. En sobreimpreso, el título de la historieta, seguido de un epígrafe: “dentro de 200 años, ¿quién se acordará de nosotros?”. Sin embargo, esta aparente precisión se ve desestabilizada a lo largo de la historieta, que hace referencia a civilizaciones e imperios que no pueden haber surgido y desaparecido en sólo dos siglos. ${ }^{13}$ Esa desestabilización de las coordenadas temporales contribuye a la construcción de un escenario situado en un futuro impreciso cuya singularidad ya se establece desde las primeras páginas. Así, la segunda página (de viñeta única, como la página tres) nos muestra la figura humanoide de la primera página avanzando por un desierto, y la siguiente un plano entero de la misma figura. Esta página, en una mezcla perturbadora de extrañeza y familiaridad que evoca el efecto de lo siniestro en la literatura fantástica de efectuar una transformación de lo familiar en extraño (Jackson 64), nos muestra al personaje (que parece una especie de cíclope con apéndices que recuerdan las orejas de un ratón) cantando una canción infantil muy conocida ("El gallo pinto se durmió...”) y expresando su incomprensión al respecto ("Me gustaría saber qué cosa es un 'cocoricó””). El mismo recurso para evidenciar la distancia del personaje con la cultura del contexto de producción de la obra se vuelve utilizar unas páginas más tarde, cuando el personaje canta otra canción (“y al final del largo día/ con un gran queso campero/ el ratón siempre volvía/ a dormir a su agujero”), y la interpreta de manera errónea: Mono (el protagonista) le cuenta a Lobo (un personaje que parece, por el momento, invisible o inexistente) que "queso campero" quería decir, en el pasado del que proviene la canción, "buen compañero” (9).

Como en Plop, el de El cuervo que sabía es un mundo en el que hasta los fenómenos naturales se han visto transformados como causa de algún tipo de cataclismo. Si en Plop el agua de lluvia es la única que puede beberse, en El cuervo la lluvia es ácida y le sirve al protagonista para recargar sus “pilas de ácido”, novum claramente cienciaficcional (4). El misterio del acompañante invisible también se resuelve en clave científico-tecnológica: Lobo (que cuando es representado toma una

\footnotetext{
${ }_{12}^{12}$ La historieta se publicó semanalmente en www.historietasreales.com.ar.

${ }^{13}$ En un guiño metaliterario, se hace referencia a la civilización de los Murkins, que pertenece a un futuro distante en la obra de Cordwainer Smith (Kráneo 61).
}

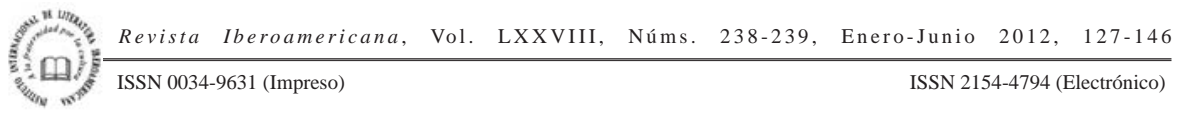


forma canina o antropo-canina) es una "esquizofrenia de compañía” (43). El mismo Lobo lo confirma hablando con Mono: "Yo estoy de tu lado, Monito... Soy tu lado, somos lo mismo" (74, enfatizado en el original). En los recuerdos de Mono que se nos muestran poco antes del final podemos ver cómo Dardo, su padre, le inocula a través del oído algún tipo de dispositivo, diciéndole que le va a dejar un amigo hasta que vuelva y que es un lobo (81). Y el cuervo del título lo confirma al definir a Lobo como "un implante esquizofrénico independiente" (86).

$\mathrm{Al}$ comienzo de este apartado se dijo que El cuervo que sabía funcionaba, de diversas maneras, como un opuesto de Plop, y esto a pesar de los mundos yermos que comparten. Y una de las diferencias principales tiene que ver con el "tono" de la historia. Si Plop es un relato duro como los residuos de hierro, metal y vidrio que, mezclados con el barro, cubren la superficie de ese mundo, El cuervo destila cariño por su protagonista y por la especie a la que pertenece (la humana), un cariño explicitado por la voz narradora en su parlamento final: "seguimos en el camino, y los recordamos con cariño y tristeza, violentos padres humanos” (96). En esta última página la voz narradora les vuelve a hablar directamente a los lectores -ya se había dirigido a los "queridos lectores del pasado" (72)- y se identifica como perteneciente a una forma de vida (natural o artificial, no se precisa) heredera de la humanidad, y dice provenir del futuro. La historieta sería entonces un testimonio desde el futuro, y el dibujante no sería más que una interfase de ésta, no del todo fácil de controlar: "los dibujos de un sistema nervioso poco confiable no siempre respondieron a mi entera voluntad" (96). Lo interesante del recurso es que, sin anular el carácter aislado del cronotopo construido, establece un lazo entre el presente del lector y el futuro de la historia. Mientras Plop enfrenta al lector con el horror de una humanidad reducida a una guerra continua de todos contra todos por la supervivencia en la que sólo se aceptan aliados circunstanciales, El cuervo que sabía retrata la permanencia de lo humano, aún más allá de su desaparición física. De hecho, la historieta se cierra con un parlamento de la voz narradora que va en ese sentido: "Quería decirte: no importa el nombre de la tormenta que asolará tu mundo y será el inicio de tu extinción. Importa que nos dieron impulso a nosotros, sus hijos, que vamos corriendo hacia el futuro que admite posibilidades, pero nunca hace una sola promesa” (96).

El cuervo que sabía es la historia del último chico humano, Mono, y sobre todo de los acontecimientos precipitados por su naturaleza humana. Mono vive sólo, sin más compañía que la (virtual) del lobo y de la "maquinik" que produce agua y comida y supervisa la tecnología que asegura su supervivencia, como la del "nanotraje” que le permite soportar un medio ambiente vuelto inapto para la vida y le da una apariencia ratonil (las orejas son captores de energía solar). La maquinik también es responsable de sintetizar drogas que impiden el desarrollo sexual, pero una falla en este cometido precipita los acontecimientos. Este desarrollo altera la existencia de Mono, hasta el

\footnotetext{
Revista Iberoamericana, Vol. LXXVIII, Núms. 238-239, Enero-Junio 2012, 127-146 ISSN 0034-9631 (Impreso)

ISSN 2154-4794 (Electrónico)
} 
momento sin otro objetivo que la mera supervivencia y marca la definitiva irrupción de lo humano. Hasta entonces, Mono vivía una existencia signada por lo animal y lo tecnológico. Como se supone hace el animal del que toma su apodo, Mono repetía acciones (que le dictaba su maquinik) sin entenderlas. Como un ratón, del que su nanotraje le daba la apariencia, vivía de sobras y hurgaba entre restos, entre los que buscaba objetos que le pedía su maquinik (12). Su desarrollo sexual cambia todo esto, como le señala la Inteligencia Artificial que Mono activa al curiosear entre los restos de una nave estrellada: "Lo que tenés es un festival de hormonas. Evidentemente, las drogas de tu maquinik fallaron, permitiendo que tus caracteres sexuales madurasen, algo complicado para un ratón” (41). Algo más adelante, la entidad confirma su suposición: "Ahora está claro. La libido no suprimida de Mono fue la que derribó este avión” (45). Más allá de la metáfora sobre la fuerza de las pulsiones, el hecho se explica en la obra por el complicado mecanismo de funcionamiento de la nave, que tiene algún tipo de contacto con un satélite que guarda "como una joya” a una chica en hibernación (80). Pero lo que prima es la postulación de la fuerza de las pulsiones y, específicamente, de la pulsión sexual: la voz narradora, en un resumen de la acción, vuelve a afirmar: “iLa libido derriba aviones!” (72). De todas formas, la atracción de Mono por el sexo opuesto no queda limitada, en la obra, al sólo aspecto sexual, y se da lugar a su costado más romántico. Cuando el protagonista recibe información de parte del cuervo (que pasa a ser un animal "que sabe" y puede comunicarse luego de ingerir una de la unidades de almacenamiento de energía del avión derribado), su visualización de la chica en hibernación en un satélite en órbita está encabezado por el epígrafe "La chica de tus sueños" (80). Y cuando Mono discute con el cuervo sobre la posibilidad de alcanzar a la chica alguna vez, la respuesta negativa del cuervo se da en clave lírica: "Quienes podrían hacerlo ya no existen, y nosotros no tenemos los medios [...]. Las ciudades de las vidis [registros audiovisuales] son canciones del pasado [...]. la chica es una canción imposible” (83). Lo que no impide que Mono se fije como objetivo alcanzar a la chica, aunque tal vez no suceda nunca.

Lo que también es interesante es que esta postulación de la importancia de los impulsos sexuales como parte constitutiva de la identidad humana no se realiza oponiendo lo humano a lo no humano, lo natural a lo artificial: el sexo (y la actividad sexual en particular) funciona también, en la historia, como un dispositivo para incorporar "mejoras" científicas que faciliten la adaptación del cuerpo humano al nuevo medio ambiente, sin necesidad de mediaciones como la del "nanotraje". La imagen que muestra la relación sexual entre Mono y una especie de clon de la chica congelada en el espacio está encabezada por la leyenda "Recuperación, transmisión y transformación de la información” (72). El cuervo parlante explica poco más tarde en qué consiste esta transformación: "En el intercambio de fluidos, ella te inoculó 600 millones de nanobots que en aproximadamente 120 segundos se convertirán en un

Revista Iberoamericana, Vol. LXXVIII, Núms. 238-239, Enero-Junio 2012, $127-146$
ISSN 0034-9631 (Impreso) 
sistema de 127.000 millones de operadores nanobóticos en tu organismo” (75). El uso de nova como "nanobots" u "operadores nanobóticos" inscribe de pleno la explicación del cuervo en un verosímil ciencia ficcional.

Otro rasgo particular de El cuervo es que, como en Plop, el cronotopo que se construye presenta rasgos de territorialización particulares vinculados con lo argentino. Estas marcas geográficas y culturales, menos abundantes que en la novela de Pinedo (lo cuál es lógico, teniendo en cuenta que en la historieta de Kráneo hay un solo personaje y un escenario prácticamente vacío), no dejan de hacerse presentes. La primera es la ya mencionada canción infantil que aparece en la tercera página, "El gallo pinto se durmió", del escritor y titiritero argentino Javier Villafañe; la segunda, omnipresente como en Plop, es el voseo. Por otra parte, la poca profusión de estas marcas de territorialización es coherente con la focalización de la historieta en la supervivencia de lo humano. ${ }^{14} \mathrm{Y}$, como sucedía en Plop, el mundo de El cuervo está constituido por fragmentos, mezclados y transformados, del mundo del pasado que ya no existe. Esos fragmentos se manifiestan en la obra principalmente de dos maneras. Por un lado, a través de las canciones y refranes que Mono repite y que pueden provenir de tipos de discurso bien diferentes del que les atribuye el protagonista; es lo que sucede con el "refrán" "Vorsprung duch technik" (traducible aproximadamente como "progreso a través de la tecnología”), que aparece dos veces a lo largo de la obra, primero en boca de Mono y luego del cuervo (Kráneo 60 y 76), y que es en realidad el slogan de la marca de autos alemana Audi. Lejos de este origen comercial, el "refrán” explica de manera literal, en el mundo de la obra, de la supervivencia del ser humano (cuyo único exponente en la Tierra parece ser el protagonista), inviable sin la ayuda de la tecnología. Efectivamente, sin su "maquinik de supervivencia”, su nanotraje y sus paneles solares primero, y sus “operadores nanobóticos” después, la vida de Mono no sería posible en el medio ambiente contaminado que lo rodea.

Otro ejemplo de adaptación de restos culturales es la canción que tararea Mono antes de dormirse en una excursión al desierto: "Lobo de la guarda/ loca compañía/ no me dejes solo/ ni de noche de día" (18). ${ }^{15}$ La segunda manifestación de fragmentos del pasado, además de los refranes y canciones, la constituyen las “vidis” que Mono

14 Es posible encontrar antecedentes de historietas emparentadas con la ciencia ficción que focalizan las pulsiones, y especialmente la sexual, como característica (y motor de la supervivencia) del ser humano. En el primer tomo de la saga La casta de los metabarones, de Alejandro Jodorowsky y Juan Giménez, Othon le trisaïeul (Othon el tatarabuelo), el protagonista que sufrió la pérdida de su aparato reproductor, logra conducir una nave espacial "gracias a su instinto", adosando el comando de la nave a su enterpierna. De manera similar, en el encuentro virtual con la inteligencia artificial que conducía el avión estrellado, Mono es salvado de hacer en el muro de fuego por un rayo luminoso que conecta su ingle con la extraña construcción a la que quiere llegar, cubierta de esculturas femeninas (Kráneo 44). En ambos casos se literaliza a través del dibujo la idea del impulso sexual como motor y como esencial para la vida.

15 La canción es una adaptación de la oración “Ángel de la guarda/ dulce compañía...”.

Revista Iberoamericana, Vol. LXXVIII, Núms. 238-239, Enero-Junio 2012, $127-146$
ISSN 0034-9631 (Impreso) 
atesora, de las cuales la mayoría son "vidis de chicas", una preferencia debida al desarrollo sexual de Mono que su maquinik defectuosa no impidió. Es interesante también que la tecnología falla para anular la libido de Mono, pero no para asegurar su supervivencia. Lo que prevalece es el impulso humano de supervivencia, incluso si esto implica una hibridación tecnológica.

El Delta Panorámico de Marcelo Cohen, ¿Un posapocalipsis Que SE IGnora a sí MISMO?

Donde yo no estaba parece situarnos, en principio, a años luz de los cronotopos de Plop y El cuervo que sabía. Y sin embargo se trata, en ambos casos, de construcciones de mundos posapocalípticos, claro que de tipos bien distintos. Las tierras devastadas de las últimas dos obras, coincidentes con el arquetipo de “tierra baldía” de la tipología binaria de Berger (5-7), son más fáciles de identificar como espacios posapocalípticos que el escenario de la novela de Cohen. Profusamente habitado, el Delta Panorámico, el mundo que Cohen crea en el libro de relatos Los acuáticos (2001) y continúa desarrollando en Donde yo no estaba, no deja de evidenciar rasgos propios de lo posapocalíptico, pero con una singularidad: el Delta Panorámico es, de alguna manera, un posapocalipsis que se ignora a sí mismo. Aparentemente un mundo perfectamente funcional, el Delta Panorámico muestra, a lo largo de las más de setecientas páginas de la novela, características propias tanto del segundo tipo de mundo mencionado por Berger, la utopía urbana, como de representaciones más tradicionales de lo posapocalíptico. Pero la novela de Cohen es atípica en varios aspectos. Por un lado, presenta una forma particular y asordinada de distopía urbana que se sitúa además, a diferencia de lo que ocurre por ejemplo en la ciencia ficción cyberpunk norteamericana, en la periferia del mundo de la ficción. ${ }^{16}$ Por otro, al construir un mundo posapocalíptico en el que la vida sigue "normalmente" consigue el efecto paradójico de un posapocalipsis casi desdramatizado. El resultado es tanto una versión de un escenario tradicional de la ciencia ficción como una reflexión metaliteraria sobre el género en el que se inscribe y con el que dialoga.

Sin índice ni capítulos, Donde yo no estaba comienza directamente con una entrada del diario íntimo que pretende ser. Así, luego de la fecha (sin mes ni año), leemos: "A veces el monitorio de casa cumple sus funciones con un celo arrasador: Hoy a la hora del desayuno, justo cuando me llevaba la taza de cafeto a la boca, el individuo se encendió en la pared para informarme de que en el techo del cobertizo de las herramientas siguen extendiéndose unas manchas de humedad” (9). Con nova

${ }^{16}$ La novela multiplica las referencias a Isla Múrmora, la isla-país del Delta en el que se desarrolla la novela, como espacio "secundario", "atrasado" (Cohen, Donde 286, 492).

Revista Iberoamericana, Vol. LXXVIII, Núms. 238-239,
ISSN 0034-9631 (Impreso) 
como "monitorio" o “cafeto”, estas primeras líneas nos sumergen en un mundo que definitivamente no es el nuestro, el mundo del lector. O, más bien, que ya no es el nuestro: los nova introducidos, lo suficientemente cercanos a objetos del mundo empírico y contemporáneo como para que podamos considerarlos como evoluciones de ellos (teniendo en cuenta que el mundo de la novela está en un estadio tecnológico más avanzado que el nuestro) colaboran en la construcción de un cronotopo posfuturista. Y esto, por supuesto, independientemente de que el Delta Panorámico sea o pretenda ser una versión futura del mundo actual o la evolución de un mundo paralelo: la construcción de la impresión posfuturista sirve para establecer una relación con los mundos de la ciencia ficción, con los que la novela dialoga. Pero no con todos: específicamente, con aquellos con los que se muestra como posapocalípticos. Y es que más allá de que el Delta sea la versión futura de "nuestro" mundo o de otro (que, de todas formas, se le parecería bastante), lo que va quedando claro a medida que avanza el relato es que el mundo de la novela sobrevivió a un cataclismo, si no material, al menos conceptual y cosmogónico, y por ende nada despreciable: en un pasado remoto, la religión (y sistema de pensamiento) dominante no era la Religión del Pensar del presente de la novela, sino otro, la del Dios Único, de la que no quedan más que algunos creyentes irreductibles y algo fanáticos. El Delta Panorámico es entonces un mundo pos-monoteísta, siendo justamente ese cambio de paradigma el cataclismo del que es sobreviviente. Pero no es ese dato el único elemento para considerar al mundo de Donde yo no estaba como posapocalíptico: a lo largo de la novela se van acumulando elementos de ese tipo de escenario, tanto en su versión tradicional (proveniente de textos religiosos) como en sus relecturas cienciaficcionales.

Entre los rasgos característicos de las representaciones más tradicionales de mundos posapocalípticos se encuentra, como habíamos comenzado a mencionar antes, la ruptura con el pasado y el fin de todo proceso histórico, el quiebre de las causalidades naturales e históricas (Raphaël 14). En la novela de Cohen, una de las maneras en las que esta atemporalidad se manifiesta es a través de la Panconciencia: la facultad, compartida por todos los habitantes del Delta, de "viajar" por una conciencia distinta de la propia (una especie de paseo, digamos, por otra mente). La sensación de ruptura de los límites temporales que proporciona la Panconciencia es señalada desde la primera experiencia narrada en la que se la describe como un "vicio que nos llena de mundos ajenos, única eternidad"17 (Cohen, Donde 76). En tanto que experiencia puramente mental, la Panconciencia separa de lo carnal, de lo material y del aquí

17 La presencia de dispositivos (tecnológicos, químicos o producto de las facultades mentales) que compiten con la realidad material es un motivo recurrente en la ciencia ficción a partir de la segunda mitad del siglo xx. En el subgénero cyberpunk, que toma a su vez muchos elementos del tipo de ciencia ficción practicada por Philip K. Dick, los artefactos generadores de realidad virtual suelen ser un elemento recurrente.

Revista Iberoamericana, Vol. LXXVIII, Núms. 238-239, Enero-Junio 2012, $127-146$
ISSN 0034-9631 (Impreso) 
y ahora, construyendo así una impresión de atemporalidad. Esa consideración de la Panconciencia como una búsqueda de la eternidad también aparece en la crítica que realiza Fusco Maraguane, el fumigador contestatario, cuando fustiga el escapismo de la "Pan":

[...] nadie quiere asumir que vive en el tiempo; quieren rapidez; puro narcisismo; náusea, irrealidad, alineación, autonomía total; anhelo de satisfacción instantánea y constante... ien esta isla de pordioseros!. [...] el narciso quiere que el tiempo culmine en una eternidad perfecta; y lo quiere enseguida; por eso la gente se relame con la Panconciencia y se olvida de la materia real, las lombrices de la tierra, las vides. (139)

Esta atemporalidad de la Panconciencia se suma a la propia del Delta Panorámico y específicamente de Isla Múrmora, que parece fijada, como señalábamos antes, en una especie de "futuro" eterno en el que ni siquiera sus propios habitantes parecen percibir el paso del tiempo, que por otra parte tampoco parece ser importante ni tener demasiada importancia. Pero si esta característica acerca al mundo Donde yo no estaba a la descripción tradicional de lo posapocalíptico, hay un rasgo fundamental que lo singulariza, y es que se trataría en todo caso de un posapocalipsis de un mundo secundario, "de pordioseros", como dice Maraguane en su diatriba.

El carácter "atrasado" de isla Múrmora es mencionado de manera recurrente a lo largo de la novela. Así Aliano, el narrador, describe a su isla como "la retaguardia provinciana del futuro" (285), con una expresión que hace referencia al atraso sociopolítico y tecnológico de la isla en comparación con otros territorios del Delta. Este "subdesarrollo" de la isla resulta importante porque participa de la construcción, junto con otros elementos, de un cronotopo en el que se insertan, ligeramente transformados, elementos de una identidad, más o menos estereotipada, argentina o latinoamericana. El anacronismo de Isla Múrmora, en la que todo lo nuevo ya es viejo en otras partes del Delta, puede y debe leerse también en clave sociopolítica.

Además del énfasis en lo periférico del lugar de la acción (Isla Múrmora) con respecto al mundo ficcional (el Delta Panorámica), Donde yo no estaba presenta otras "marcas de territorialización" del cronotopo cienciaficcional que utiliza y transforma. Como en Plop y El cuervo que sabía, las marcas idiomáticas toman la forma del voseo. Como en esas obras, la lengua del mundo ficcional está enrarecida por neologismos. También hay marcas culturales, como una de las maneras en que se bebe la omnipresente infusión de yecle: en ronda, en cáscara de calabaza, sorbido con una caña (560), en una referencia inequívoca a la manera tradicional de preparar y tomar la yerba mate, consumida de la manera descrita principalmente en Argentina, Uruguay y el sur de Brasil. La imagen del delta, por último, si no es una característica identificatoria de los argentino sí lo es de lo rioplatense, como el mate y el voseo.

\footnotetext{
(3) Revista Iberoamericana, Vol. LXXVIII, Núms. 238-239, Enero-Junio 2012, 127-146 ISSN 0034-9631 (Impreso) ISSN 2154-4794 (Electrónico)
} 
Más allá de las diferencias de "tono" y de foco del relato entre El cuervo y Plop, en ambas obras, en tanto suceden en mundos devastados, ocupa un lugar esencial la lucha por la supervivencia (de la especie humana en un caso, de los individuos en el otro). En el mundo de Donde yo no estaba, en el que si hubo un cataclismo (y parece haberlo habido, al menos en lo concerniente a una visión del mundo) sucedió hace tanto tiempo que la memoria se ha perdido, no es extraño que esto no sea así. Y es que si los protagonistas de las obras de Kráneo y Pinedo deben vivir sobre las ruinas de un cataclismo devastador, en la novela de Cohen los eventos que desencadenan la acción carecen de cualquier dimensión monumental. Por más extraños que sean los acontecimientos que la singularidad del mundo de Donde yo no estaba permita, los hechos que impulsan a Aliano a realizar las acciones principales de la novela (proteger a un fugitivo de las autoridades y realizar un largo periplo por la isla) no tienen nada de cienciaficcionales. Efectivamente, lo que aleja a Aliano de su rutina son sucesos de lo más prosaicos: una separación y una enfermedad potencial y aparentemente mortal. Aliano se sitúa en las antípodas de Plop y Mono, movidos ambos por objetivos concretos y puntuales: al protagonista de Donde yo no estaba la acción le sucede, le ocurre sin que él la haya buscado. Y la única vez que aparece la palabra "apocalipsis" en el texto es para un evento tan poco extraordinario, tan propio de "nuestro" mundo real y concreto como el robo de un vehículo. El robo de su cocheciño es para Aliano su apocalipsis particular, alejadísimo del final catastrófico, pero con posibilidad de redención en el que creen los fieles del Dios Solo (556-57). Su propio apocalipsis, escribe Aliano, carece de visión, de verdad, de revelación y de redención. La pérdida del vehículo, último resabio de su vida anterior (su mujer lo dejó, debió mudarse, uno de sus hijos se mudó a una ciudad lejana) lo deja "en tierra de nadie entre el Dios solo y el Yud” (557). Porque ese es el desierto, la tierra baldía que habita Aliano: una tierra de nadie conceptual, que lo aísla de los adherentes de una y otra religión y visión del mundo.

Conclusión. El aislamiento COMO CATALIZAdor DE LA ESPECIFICIDAD DEL MUNDO DE FICCIÓN

Toda apropiación de un género dado desde coordenadas geográficas y culturas distintas de las de su origen requiere, para no caer en una simple repetición de modelos, de una adaptación. Las obras aquí analizadas, más allá de sus singularidades y diferencias, comparten hasta cierto punto determinadas estrategias de adaptación. Por un lado, la inclusión de marcas culturales, idiomáticas y geográficas que distingen a los cronotopos construidos de los escenarios típicos de las formas de ciencia ficción con las que dialogan. Por otro, la decisión de descartar un elemento recurrente en muchas obras de ciencia ficción: la advertencia sobre las consecuencias de tal o

\footnotetext{
Revista Iberoamericana, Vol. LXXVIII, Núms. 238-239, Enero-Junio 2012, 127-146 ISSN 0034-9631 (Impreso)

ISSN 2154-4794 (Electrónico)
} 
cual conducta humana. En efecto, ninguna de las obras analizadas incluye la más mínima información sobre la naturaleza del evento causante de la extinción de la civilización previa al presente de la acción. En todos los casos se deja completamente de lado el costado predictivo, concentrándose en el posapocalipsis y desentendiéndose completamente de sus causas. Esta elección tiene dos lecturas posibles. En primer lugar, puede leerse como la postulación fatalista de la imposibilidad de impedir las catástrofes. En segundo lugar, y de manera opuesta pero también complementaria, como una declaración de descreimiento frente a los finales taxativos, definitivos. En Plop, la caída en desgracia del protagonista, condenado a muerte, se debe a su imposibilidad de captar las señales de cambio en su grupo, de pretender perpetuar el contexto que le permitió ascender al poder. ${ }^{18}$ En El cuervo que sabía, la pulsión vital de su protagonista abre la posibilidad de que la especie humana no esté, en el momento del relato, definitivamente condenada. Y Donde yo no estaba nos presenta un mundo en el que la caída de un paradigma dominante no parece haber cambiado demasiado a sus habitantes. La contradicción típica del relato pos-apocalíptico (la presencia de un “algo” más allá del fin) se resuelve en la negación de ese fin.

Es importante mencionar antes de concluir que el aislamiento mencionado para caracterizar a los cronotopos de las tres obras se declina también de una forma distinta: en la ausencia de elementos exógenos, un tema tradicional de la ciencia ficción. Ninguno de los actantes de los tres relatos tiene un origen externo, ni siquiera el avión que derriba Mono en El cuervo (el avión tiene un lazo con quienes construyeron el satélite donde hiberna la chica, también humanos). No hay extraterrestres, por ejemplo, y ni siquiera las inteligencias artificiales que sucederán al hombre en El cuervo se muestran como algo radicalmente distinto (recordemos que la IA que parece ser el narrador de la historia se dirige a sus "padres humanos"). Esta ausencia no es menor, ya que es justamente la presencia de un adversario externo, inexistente en las obras analizadas, lo que permite construir un "nosotros" inclusivo. De hecho no existe, en ninguno de los relatos, un "afuera" con respecto al escenario de la acción. El basural de Plop, el desierto de El cuervo y el Delta Panorámico en Donde yo no estaba son el mundo, a los efectos del relato. Si existe un "afuera" de esos espacios, no es así para el relato. Hasta en el espacio comparativamente extenso de la novela de Cohen lo que resalta es lo que queda fuera. Un delta es forzosamente un recorte y, sin embargo, no hay mares a la vista. Las tres obras optan por la mirada micro, el recorte extremo, en la construcción tanto del escenario como del foco de la acción, confluyendo en una adaptación de modelos de género que prescinde de los formatos a gran escala. Ese recorte no hace más que acentuar la impresión de un mundo ficcional elaborado

${ }^{18}$ La novela da cuenta de las numerosas oportunidades en que Plop no ve o no quiere ver los cambios sociales en su grupo, entre ellos una menor aceptación de la violencia.

$\begin{array}{lllll}\text { ISSN 0034-9631 (Impreso) } & \text { ISSN 2154-4794 (Electrónico) }\end{array}$ 
"con lo propio", para completar el efecto de un cronotopo cienciaficcional poblado de marcas de territorialización que lo distinguen de otras construcciones más propias del mainstream.

\section{BiBLIOGRAFÍA}

Bajtin, Mijail M. "Forms of Time and the Chronotope in the Novel". 1930. The Dialogic Imagination. Caryl Emerson y Michael Holquist, ed. y trad. Austin: U of Texas P, 1981. 84-258.

La cultura popular en la Edad Media y el Renacimiento. El contexto de François Rabelais. Julio Forcat y César Conroy, trad. Madrid: Alianza, 1999.

Berger, James. After the End: Representations of Post-Apocalypse. Minneapolis: U of Minnesota P, 1999.

Coelho, Oliverio. Promesas naturales. Buenos Aires: Norma, 2006.

Cohen, Marcelo. Los acuáticos. Buenos Aires: Norma, 2001. Donde yo no estaba. Buenos Aires: Norma, 2006.

Gibson, William. Neuromancer. Nueva York: Ace Books, 1984.

Greimas, A. J. Sémantique structurale. 1966. Paris: PUF, 1986.

Jackson, Rosemary. Fantasy: The Literature of Subversion. Londres: Methuen, 1988.

Jodorowsky, Alejandro y Juan Giménez. Othon le trisaïeul. Paris: Les Humanoïdes Associés, 1992.

Kermode, Frank. The Sense of an Ending. Nueva York: Oxford UP, 1967.

Kráneo, Kwaichang. El cuervo que sabía. Word Press. 2008-2009. <www. historietasreales.com.ar>. 1 enero 2010.

Malmgren, Carl D. "Worlds Apart: A Theory of Science Fiction". Utopian Thought in American Literature. Arno Heller, ed. Tübingen: Narr, 1988. 25-42.

Pinedo, Rafael. Plop. Buenos Aires: Interzona, 2006.

Raphaël, Freddy. "Esquisse d'une typologie de l'apocalypse”. L'apocalyptique. F. Raphaël, et al. Paris: Librairie Orientaliste paul Geuthner, 1977. 11-38.

Reati, Fernando. Postales del porvenir. La literatura de anticipación en la Argentina neoliberal (1985-1999). Buenos Aires: Biblos, 2006.

Smith, Cordwainer. The Rediscovery of Man. John J. Pierce, ed. Framingham: NESFA, 1993.

Steimberg, Alejo. "El posapocalipsis rioplatense de Marcelo Cohen. Una lectura de Donde yo no estaba”. Imaginarios apocalípticos en la literatura hispanoamericana (Siglos $X X$-XXI). Geneviève Fabry, Ilse Logie, Pablo Decock, eds. Oxford-Bern: Peter Lang, 2010. 245-255.

Suvin, Darko. Metamorphoses of Science Fiction. On the Poetics and History of a Literary Genre. New Haven: Yale UP, 1979.

Revista Iberoamericana, Vol. LXXVIII, Núms. 238-239, Enero-Junio 2012, $127-146$
ISSN 0034-9631 (Impreso) 
Pour une poétique de la science-fiction. Montréal: Presses de l’Université du Québec (P.U.Q.), 1977.

Villafañe, Javier. El gallo pinto y otros poemas. Buenos Aires: Colihue, 2005.

Sevista Iberoamericana, Vol. LXXVIII, Núms. 238-239, Enero-Junio 2012, 127-146 ISSN 0034-9631 (Impreso) ISSN 2154-4794 (Electrónico) 